\title{
Before You Record Anything Else: Topics and Questions to Consider When You Interview a Speaker for the First Time
}

\author{
SUZANNE WASH \\ University of California, Davis
}

\section{Introduction}

In recent years there has been a renewed interest in field linguistics and language documentation. One reflection of this trend is the appearance of several relatively new books about doing linguistic fieldwork (e.g. Newman and Ratliff 2001, Vaux and Cooper 1999, Payne 1997). Yet, there remains one area of fieldwork methodology that is rarely dealt with in publications and linguistic field methods courses generally: how and why a linguist should gather information about the life history of the speaker, including, especially, information about the speaker's sociolinguistic background. Such information is critical for linguists investigating moribund languages, where it is not uncommon to find significant differences in the speech of speakers who belong to the same family, let alone the same speech community. The reasons behind such differences become clearer if the linguist first determines what sociolinguistic factors, in the speaker's personal history, have affected that speaker's knowledge and use of the language in question.

To deal with this area of inquiry, I developed the oral questionnaire given in the following pages of this article. With the exception of section 1.2.4., which is a relatively recent addition, I have used this questionnaire in my fieldwork with some of the last speakers of Northern Sierra Miwok, a moribund California Indian language. This language was formerly spoken in an area that now roughly includes the counties of Amador and Calaveras in California.

I first started doing fieldwork among speakers of Northern Sierra Miwok in 1992, when I was a graduate student in linguistics at the University of California, Santa Barbara. I did not become aware of the importance of recording sociolinguistic information about speakers until 1995, when I started working as a research assistant for the Corpus of Spoken American English, headed by John W. Du Bois. Under this project, researchers were sent out across the United States to record naturally spoken American English. The researcher who made the recording would collect information about each speaker's background on a brief, speaker information form. Among other areas of inquiry, this form asked about the speaker's native language(s), including the speaker's first and/or dominant 
language, age, occupation, education, religion, language used during school, residence history, the speaker's parents' place of origin, and parents' native language(s). I realized that if such background information were important for research on a world language like English, how much more important must it be for research on an endangered language like Northern Sierra Miwok? The resulting oral questionnaire is thus inspired from Du Bois' speaker information form, but it is modified and greatly expanded for working with speakers of Northem Sierra Miwok. The format is general and flexible enough, however, that it can be easily customized for working with speakers of any language.

This oral questionnaire will help you obtain critical information about the speaker's sociolinguistic background and history of language use before you begin detailed investigations of the language in question. For example, you will find out what languages the speaker knows or has otherwise been exposed to, the contexts in which the speaker learned and used these languages, and the extent to which the speaker has used these languages. You will gain an insight into the differences perceived by the speaker between his or her language and the languages of nearby communities which the speaker may know. You can obtain a better understanding of the speaker's attitudes about speaking particular languages, and what factors shaped those attitudes. For moribund languages, the questionnaire helps you obtain information about the number of other speakers there may be and their degree of fluency in those languages. Finally, in cases where members of the same family show unexpected differences in the way they speak a given language, this questionnaire will help you discover the reasons for such differences. In one particular family whose members speak Northern Sierra Miwok, I found that the pronominal paradigm for one of the speakers showed unexpected similarities with the pronominal paradigm of Central Sierra Miwok, a closely related language. The similarities stem in good part from the fact that this particular speaker spent a significant amount of his childhood living with his paternal grandmother, who spoke to him in Central Sierra Miwok. His parents did not speak to him in that language. Without this questionnaire, I might not have ever found out these particular but crucial facts about his history of language use.

\section{The Oral Questionnaire}

\subsection{Preliminaries: What to say when you first start the recording}

When you first start the recording, it is a good idea to state the date, the name of the speakers(s) you're interviewing, your name, and the place of the interview. Regarding the place of the interview, include particulars such as the town and state or province in which it is located. State also whether the interview is taking place in the speaker's home, or in a public place such as a park. Mention the name of anyone who is assisting you in the recording process, such as the person attending to the video camera. Are there listeners in attendance? If so, mention this fact, and identify them on the recording if circumstances allow it.

State the number of the tape or disk that you are using for that day's recording session. For example, if you're starting on the first tape of that day's session, say 
into the tape recorder This is tape number one. Likewise, say This is tape number three if you have already recorded two tapes during that same interviewing session and you are starting on the third tape.

Record the above preliminary information every time you begin a new tape and/or recording session. Doing so will save you from some hassles later on, especially if the tapes or disks are unlabeled and get stacked out of sequence in your equipment bag.

\subsection{Questions about the speaker's age, residence- and work history, education, and religion}

\subsubsection{Age and residence history}

(1) When were you born?

(2) Where were you born?

(3) Could you tell me the places you have lived throughout your life, about how long you lived in each place, and who you lived with during these times? Start with your place of birth. (Note: Make a list of the people the speaker has lived with, because you will later want to ask about the languages that the speaker has used with each of these people.)

\subsubsection{Formal schooling and language use}

As is well known, formal schooling had a great, negative impact on the lives and native languages of many Native Americans, especially those who were forced to attend boarding schools in earlier times. The questions in this section were aimed at discovering what the formal schooling experience was like for the Northern Sierra Miwok speakers I interviewed, with a special focus on language use.

(4) Did you attend school in your youth?

(5) At what age did you begin going to school?

(6) At what age did you stop going to school?

(7) The school(s) you attended, were they located near your home, or were they boarding schools located some distance from your home? (Note approximate locations.)

(8) Did you live at home while going to school?

(9) What was/were the language(s) of instruction in the classroom? 
(10) What was the ethnic make-up of your classmates? Were they mostly Indian (if so, from what communities), white, or other (e.g. Chinese or Mexican)?

(11) Did your classmates speak languages other than English?

(12) Did they speak languages other than English inside the classroom?

(13) Did they speak languages other than English outside the classroom, e.g. on the playground?

(14) Did you ever talk in Indian while at school to your classmates or to your teacher? (Note: The Miwok elders I have worked with often used the term Indian to refer to the Northern Sierra Miwok language, so that is the term I use in question (14) and elsewhere in this questionnaire.)

(15) Did your teacher and classmates know you were Indian?

(16) Were you ever punished or otherwise discouraged from speaking in Indian?

(17) Did your teacher or classmates ever encourage you to speak in Indian, or teach them some of the language?

(18) After you left school, would you say you spoke in Indian with your family just as much as you did before you entered school as a child, or did you talk in the language much less often than before? Would you say the same was true for your friends or other members of your family who attended school?

\subsubsection{Work history and language use}

(19) What kinds of work have you done throughout your life, starting with the work or chores you would do with your family and relatives as a young man/woman?

(20) Did your bosses and co-workers know you were Indian?

(21) Did you ever speak with your bosses and co-workers in Indian? If yes, did you do so while working, or did you do so only after hours?

(22) Did any of your non-Indian bosses/co-workers understand the language? 
(23) Were there only certain times or situations that you would speak in Indian at work? (Possible examples of such situations include greeting friends, joking around, arguing, or wanting to say something without other people understanding, etc.) Or, would you converse in Indian as often as you would in English? What kinds of things would you say or talk about in Indian?

(24) Did people at your work place ever encourage you to speak in Indian or teach them some of the language?

(25) Did anyone ever ask you not to speak in Indian?

(26) What other languages did you use at work?

(27) Where there some languages you heard but didn't speak yourself?

\subsubsection{Religion and language use}

This part of the questionnaire is a relatively recent addition. I added it because a growing number of Native Americans, whose language of heritage is no longer spoken, nonetheless desire to pray in their language of heritage. Therefore I believe it is an area of inquiry that a linguist should cover if at all possible. To my great regret I neglected to ask my most fluent Northern Sierra Miwok consultants, who are now deceased, about this very important aspect of language use.

(28) Did your family practice any particular faith or religion while you were growing up?

(29) Do you practice the same faith/religious traditions today?

(30) What language did you hear people use in ceremonies, prayers, or blessings?

(31) Is there any particular language you or your family members prefer to use when you pray?

(32) About how often do you pray in this language?

(33) Have you yourself ever said prayers in public or in group gatherings? In what language did you say these prayers?

(34) Would you be interested in recording some blessings and prayers, ones you say and ones you have heard others say? 
If the speaker answers yes, then the following are some suggestions that might help the speaker remember specific blessings or prayers, for either now or in a future recording session:

- Prayers expressing thanks

- Prayers or blessings appropriate at Indian Big Times/Powwows

- Blessings or prayers during opening/closing ceremonies

- Blessing for a new baby or addition to the family

- Blessing a home and the land the home is on

- Blessings/prayers at coming-of-age ceremonies or other rites of passage, such as graduations

- Blessings/prayers at weddings

- Prayers said at funerals or memorial services

- Prayers for spirits whose burial place has been disturbed

- Prayers to restore harmony and peace

- Prayers for guidance and wisdom

- Prayers for healing

- Prayers used in addressing a plant or tree that you wish to harvest from or cut down

- Prayers used in addressing a river, or the ocean, before you take fish or other food from it, or before you traverse it

- Prayers used for more/less rain or snow

- Prayers used before any undertaking, such as a long journey, a hunt, building a house, etc.

- Translations of other blessings or prayers, such as the Lord's Prayer

\subsection{Questions about the speaker's mother}

(35) Speaker's mother's name:

(36) Her date of birth:

(37) Her place of birth:

(38) Where did your mother live throughout her life?

(39) What languages did/does she speak?

(40) About how often did you hear her speak these languages with other people? 
(41) Were there any languages she could understand but did not speak herself?

(42) What language(s) did/does she speak with you?

(43) How often (i.e. daily/weekly/occasionally)?

(44) When (what kinds of contexts) would she most often talk in Northern Sierra Miwok (or in other indigenous languages) with you? (Possible examples: while telling you to do chores, telling you stories, talking with you during the preparation of meals, during mealtimes, scolding you, joking around, gathering basketry materials, making baskets, or around people who didn't know the language so that she could say something to you without others listening in, etc.)
a. During your childhood:
b. During your youth/teen years:
c. During your adult years:

(45) When (what kinds of contexts) would she most likely speak in English (or Dominant Language $\mathrm{X}$ ) with you?
a. During your childhood:
b. During your youth/teen years:
c. During your adult years:

(46) Did she ever discourage you from speaking in Indian or in English?

(47) In your best estimation, what were her thoughts and attitudes about speaking in Indian versus in English?

\subsection{Questions about the speaker's father}

Ask the same questions given in section 1.3., but for the speaker's father.

\subsection{Questions about the speaker's grandparents}

Ask the same questions given in section 1.3., but for the speaker's grandparents.

\subsection{Questions about the speaker's aunts, uncles, and acquaintances of his/her parents' generation}

Ask the same questions given in section 1.3., but for the speaker's aunts, uncles, and others of the speaker's parents' generation whom the speaker has talked with or listened to. 


\subsection{Questions about the speaker's siblings, cousins and acquaintances of his/her generation}

Ask the same questions given in section 1.3., but for the speaker's siblings, cousins, and friends or acquaintances of the speaker's generation.

\subsection{Questions about the speaker's spouse(s) and in-laws}

Ask the same questions given in section 1.3., but for the speaker's current spouse, former spouse(s) and in-laws, regarding the extent to which the speaker spoke with these people in the languages in question.

\subsection{Questions regarding the speaker's perception of and exposure to languages of nearby communities}

The following are examples of questions I have asked of elders who live in or come from Calaveras County, California, and who speak what they themselves call Calaveras, a dialect of the Northern Sierra Miwok language. The questions and subsequent answers help me understand more about a speaker's particular dialect and idiolect, and whether that speaker perceives this language to be more or less like another, nearby Miwok language or dialect that the speaker has spoken or heard. You can customize these questions in your own interviews to make them more appropriate to the homeland of the speaker you are interviewing.

(48) Is it easier for you to understand people who speak Tuolumne (Central Sierra Miwok), or is it easier for you to understand people from Amador County (who speak a different dialect of Northern Sierra Miwok), especially those from the Ione area?

(49) Does the Calaveras language strike you as being more like the Tuolumne language, more like the Amador language, or equally like both of them?

(50) In general, do you think you spent more time around Tuolumne-speaking people or Amador-speaking people, or not much time with either group, during your life?

(51) Could you do an imitation of someone speaking in Tuolumne and someone speaking in Amador?

(52) Are there other places where you spoke or heard a Miwok language spoken (e.g. at Big Times, in town, at the health clinic, the grocery store, in a bar, etc.)?

(53) Have you ever heard the Mariposa (Southern Sierra Miwok) language, and can you speak it?

(54) Have you ever spoken or heard any other American Indian languages? 


\subsection{Questions about the speaker's use of language with his or her children, grandchildren, nieces, nephews, and others of their generation}

(55) Do you or have you spoken to children (your own or others) in Indian?

(56) When your children were young, did you talk to them solely in Indian, or in both Indian and English?

(57) Were there particular contexts in which you would speak only in Indian or only in English with them?

(58) Is there anything you remember about how people used to talk to babies and children in the Indian languages you know?

(59) Did the children you spoke with answer you in Indian, or did they answer in English or Spanish?

The speaker's answers to the questions in (60) - (62) will give you a clearer idea of how to make your future recordings as relevant as possible to languagerevitalization programs that the speaker's community has or wishes to develop.

(60) Would you be interested in making recordings that could be used to help the younger generation learn your language?

(61) Would you like to teach your language to younger members of your community?

(62) What kinds of things would you like to see happen or not happen, in the future, with regard to your native language(s) and the traditional knowledge and history of your community? What role would you like to have in these efforts? For example, would you like to see these languages taught in the schools? Would you like to see bilingual signs (using your language) throughout town? Would you like to help the general public develop a greater awareness of your language, traditions, history, and community (e.g. through adult education classes for the general public or through language tutorials on the world wide web)?

Other suggestions for the list in (62) could of course include a user-friendly dictionary, illustrated books that have bilingual stories with accompanying exercises, or multimedia materials on CD-ROM. Even if the speakers you work with are not interested in having or creating language teaching materials, their future descendants might well be, especially if the language in question is endangered. 


\section{Final remarks on using this questionnaire}

There are several things to keep in mind when using this oral questionnaire:

First, it can easily take more than one, two-hour recording session, depending upon how much detail the speaker wishes to give in answering the questions. In my own fieldwork on Northern Sierra Miwok, this questionnaire has taken several recording sessions. Since Northern Sierra Miwok is a dying language, I encouraged the elders to feel free to expand upon any of the topics as they saw fit. I also told them to pass on any topic or question that they did not care to talk about.

Second, you can and should customize the questionnaire to fit the languages and experiences of the speakers you are interviewing. For example, if the speaker you are interviewing never had any formal schooling, you can change most of the questions to focus on any other kind of specialized training or apprenticeship the speaker may have had, and his or her experiences with language use therein. Or, to give another example, if you want to ask the speaker some questions about religion and language use (section 1.2.4.), but there is no direct translation for the English words blessing, pray or prayer in that speaker's language, then simply use terms from languages that the speaker knows and that convey the closest meaning to these words, in the context of the speaker's own culture and experiences. A third example of how you could customize this questionnaire concerns the questions about the speaker's relatives and their language use with the speaker. In some cultures, it is inappropriate to say the names of deceased relatives. (Such was true in traditional Miwok societies, though most of the speakers I interviewed no longer followed that custom.) Simply delete the question that asks for the name of anyone who happens to be deceased, in that case, and use an appropriate kinship term, e.g. maternal grandmother, as a substitute for the name of the speaker's deceased maternal grandmother, when you need to refer to the deceased person. As for the wording of the questions generally, I encourage anyone who uses this questionnaire to put the questions into his or her own words, in whatever way is more comfortable to say.

Finally, as the title of this paper suggests, I recommend using the topics and questions in this oral questionnaire as a starting point in linguistic fieldwork. The questionnaire allows you to gather, in a systematic fashion, the kind of information that will contextualize the rest of the linguistic data that you obtain from the speaker. And, if you work on a language whose most competent speakers are elderly, as is often the case with endangered and moribund languages, you risk losing the opportunity to obtain this crucial information if you wait too long. 


\section{References}

Newman, Paul \& Martha Ratliff (eds.). 2001. Linguistic fieldwork. Cambridge University Press.

Payne, Thomas E. 1997. Describing morphosyntax: A guide for field linguists. Cambridge University Press.

Vaux, Bert \& Justin Cooper. 1999. Introduction to linguistic field methods. Munich: Lincom Europa.

Native American Language Center

Department of Native American Studies

University of California, Davis

Davis, CA 95616

swash@ucdavis.edu 